\title{
High responsive giant magnetostrictive materials thin film
}

\section{高応答性を有する超磁歪薄膜の作製}

\author{
Jamadil Azwad PAZAER, Koji MAKITA and Tempei TANAKAMARU \\ Department of Applied Science, Graduate School of Engineering, Tokai University, 1117 Kitakaname, \\ Hiratsuka, Kanagawa, 259-1292 Japan \\ TEL: $x 81-463-58-1211$ (EX.4151)
}

Shunichi NABEYA and Yoshihito MATSUMURA

Department of Applied Science, School of Engineering, Tokai University, 1117 Kitakaname, Hiratsuka, Kanagawa, 259-1292 Japan

TEL: x81-463-58-1211 (EX.4151) e-mail: ncc1701d@keyaki.cc.u-tokai.ac.jp

( Received 31, January 2008 Accepted 9, October 2008 )

\begin{abstract}
Magnetostrictive properties of Sm-Fe-N and Sm-Fe-C giant magnetostrictive material (GMM) thin film have been systematically investigated in this study. Film samples were prepared by d.c. magnetron sputtering process in Ar- $\mathrm{N}_{2}$ or $\mathrm{Ar}-\mathrm{CH}_{4}$ gases atmosphere. Saturated magnetostriction of formed thin films was decreased with increasing of $\mathrm{N}_{2}$ and $\mathrm{CH}_{4}$ partial pressure because of formation of non-magnetic SmN or $\mathrm{SmC}_{2}$ phases. Maximum value of magnetostrictive susceptibility is $34 \mathrm{ppm} / \mathrm{kAm}^{-1}$ was observed in Sm-Fe-C thin film sample with 1.0 vol\% $\mathrm{CH}_{4}$ gas partial pressure. Compressive stress of thin film samples was increased due to the increasing of $\mathrm{N}_{2}$ and $\mathrm{CH}_{4}$ gases pressure. The increasing of compressive stress with small $\mathrm{N}_{2}$ and $\mathrm{CH}_{4}$ addition amount into thin film samples may influence the increasing of magnetostrictive susceptibility.
\end{abstract}

Keywords: giant magnetostrictive material, samarium, ion, nitrogen gas, methane gas, thin film, reactive magnetron sputtering

\section{INTRODUCTION}

磁歪とは磁性体の特性の一つであり、磁場を印加する ことにより、外形寸法か変化する現象である。代表的な 強磁性体は鉄で $10 \mathrm{ppm}$ 程度の変位量を示す。近年、Clark らによって室温で 1000ppm 以上の巨大な磁歪量を示す 希土類 - 遷移金属系化合物が報告されている。 ${ }^{1.4}=の$ 希土類 - 遷移金属系化合物は超磁歪材料と呼ばれ変位量、 発生応力が大きく、応答速度に優れるといった特徵を持 ち、電場または磁場て駆動するため、遠隔操作を行うこ とも可能である。

SAS Award (Prize for an Excellent Work) was given to this paper presented as Poster Presentation at the 2007 SAS Intelligent Symposium.
これまで、マイクロマシンのアクチュエーターやセン サーへの応用を目指して超磁歪材料を薄膜化を行ってき た。超磁歪材料薄膜の研究は樣々な成膜プロセスによっ て行われており、成膜プロセスや成膜条件により年の磁 歪特性に強い影響を与えることが知られている。 えて、スパッタリング法を用いて作製した薄膜は作製条 件により、引つ張り応力や圧縮応力を示す。11 また、超 磁歪材料は内部応力により磁歪特性が大きく変化する事 が知られている。12-14 我々はこれまでに樣々な方法で 磁歪特性の向上を試み、薄膜の内部応力が磁歪特性に影 響を与えることを明らかにしてきた。15 そこで、本研 究では、Sm-Fe 薄膜の内部応力を制御するために常温で 気体として得る事ができる窒素ガスまたはメタンガスを 
スパッタリングガスに混合し、室素または炭素原子を Sm-Fe 原子間に固溶させ超磁歪薄膜の磁歪感受率の向上 を目指した。

\section{EXPERIMENTAL}

本研究では d.c.マグネトロンスパッタリング法を用い Sm-Fe 薄膜を作製した。d.c.マグネトロンスパッタリング 装置図の模式図を Fig.1.に示す。

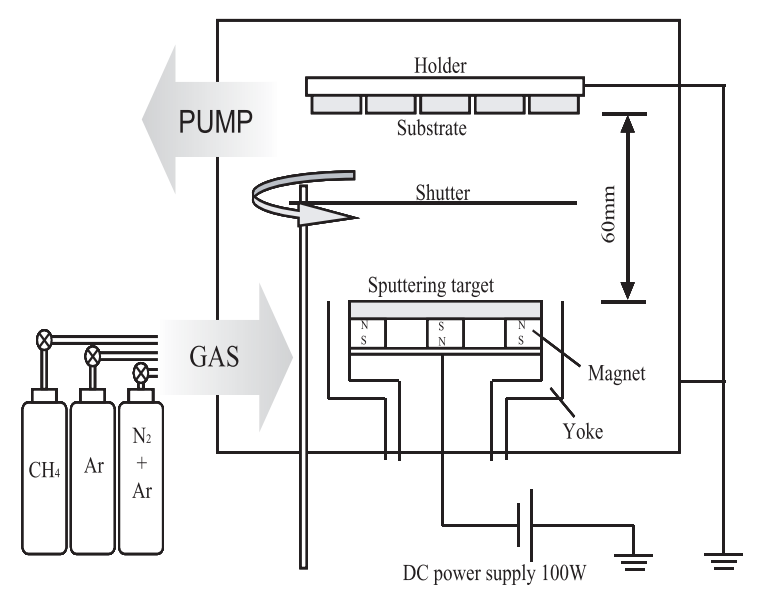

Fig. 1. d.c. magnetron sputtering system

装置内の到達真空度は $1.0 \times 10^{-4} \mathrm{~Pa}$ 以下とし、基板に単 結晶 $\operatorname{Si}(100)$ 短冊 $(5 \times 25 \mathrm{~mm}) 、$ スパッタリングターゲット に $\mathrm{SmFe}_{2}$ 合金ターゲットを用い、基板-ターゲット間距 離を $60 \mathrm{~mm}$ にした。導入ガスにアルゴンガス(純度 99.999\%)、反応性ガスとしてアルゴンと窒素の混合ガス ( 窒素の混合率 5\%、室素の純度 99.99\%) またはメタンガ ス (純度 99.99\%)を用い、成膜中のスパッタリングガス圧 を $1.0 \times 10^{-1} \mathrm{~Pa} て ゙$ でった。また、成膜時間は $3600 \mathrm{~s}$ とし、

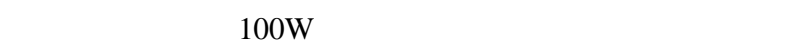
窒素ガス( $1.0 \mathrm{vol} \%$ から $4.8 \mathrm{vol} \%$ )を混合した薄膜、アル ゴンガスにメタンガス( $0.5 \mathrm{vol} \%$ から $3.0 \mathrm{vol} \%)$ を混合 したものを关れ光れ作製した。作製した試料の評価は、 組成分析にエネルギー分散型 $X$ 線分光装置(EDX)、結晶 構造の解析にX 線回折装置(XRD)を用いた。膜厚測定は 表面粗さ計(DECTAK3)を用い、磁歪特性は光てこ法を用 いて試料の反りを測定し算出した。 ${ }^{16}$ 内部応力は基板の 反り測定から求めた。

III. Results and Discussion III-A. Magnetostrictive Characteristics of Sm-Fe-N and Sm-Fe-C Thin Film
スパッタリングガスに窒素ガスまたはメタンガスの混 合により作製した各 Sm-Fe 薄膜の飽和磁歪量を Fig.2.に、 Fig.3.に同樣に作製した各 Sm-Fe 薄膜の磁歪感受率を示 す。

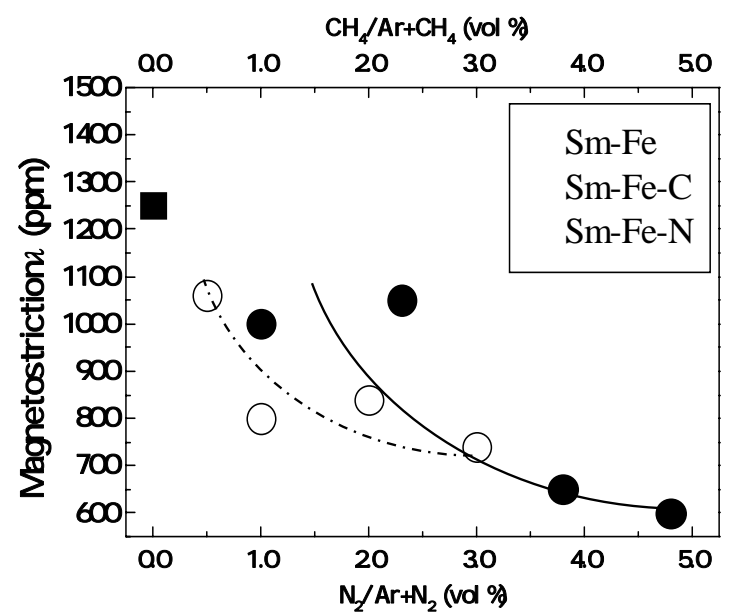

Fig. 2. Saturated magnetostriction of Sm-Fe-N and Sm-Fe-C Thin Film

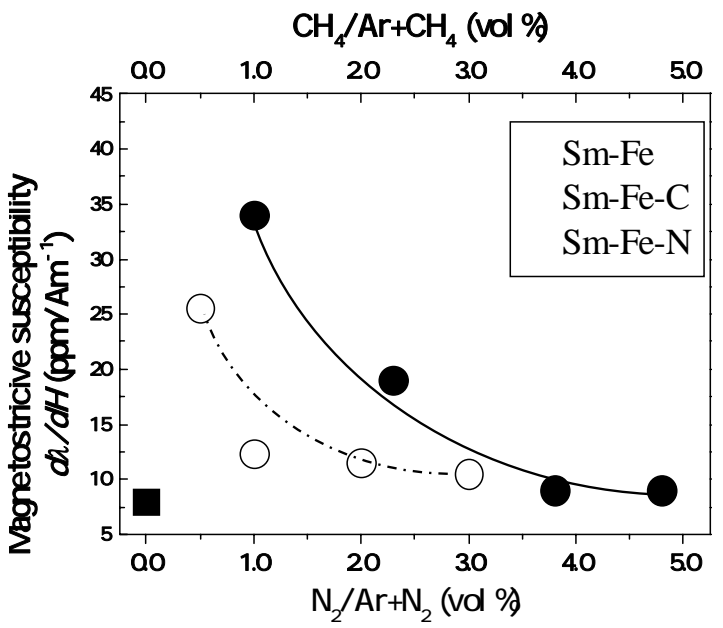

Fig. 3. Magnetostrictive susceptibility of Sm-Fe-N and Sm-Fe-C Thin Film

飽和磁歪量の結果から Sm-Fe 薄膜に対する窒素ガス混 合量が増加するのに伴い Sm-Fe-N薄膜の飽和磁歪量が低 下した。同樣に Sm-Fe 薄膜にメタンガスを混合した場合 も同樣の結果が得られた。

Sm-Fe 薄膜製膜時のアルゴンガスに対する窒素ガス混 合量が $1.0 \mathrm{vol} \%$ \%いて最も高い磁歪感受率を示したが、 $1.0 \mathrm{vol} \%$ 以上の混合量では、窒素ガス混合量の増加に伴 い磁歪感受率が低下した。また、メタンガスを用いた場 合では、メタンガス混合量が $0.5 \mathrm{vol} \%$ \%おいて最も高い 磁歪感受率を示したが、0.5 vol \%以上の混合量では、メ 
タンガス混合量の増加に従って磁歪感受率が低下し室素 ガスと同樣な傾向が見られた。この元素の微量混合によ って得られた最高磁歪感受率、最大飽和磁歪量の結果を まとめたものを Table.1.に示す。

Table 1. Magnetostrictive Characteristics of Sm-Fe-N and Sm-Fe-C Thin Film

\begin{tabular}{|c|c|c|c|}
\hline & Sm- Fe & Sm- Fe- N & Sm- Fe- C \\
\hline $\begin{array}{c}\text { magnetostrictive } \\
\text { susceptibility } \\
\left(\mathrm{ppm} / \mathrm{Am}^{-1}\right)\end{array}$ & 8 & 34 & 26 \\
\hline $\begin{array}{c}\text { saturated } \\
\text { magnetostriction } \\
(\mathrm{ppm})\end{array}$ & 1250 & 900 & 1060 \\
\hline
\end{tabular}

III-B. Internal Stress of Sm-Fe-N and Sm-Fe-C Thin Film

スパッタリングガスに窒素またはメタンガスの混合に より作製した各 Sm-Fe 薄膜の内部応力を Fig.4.に示す。

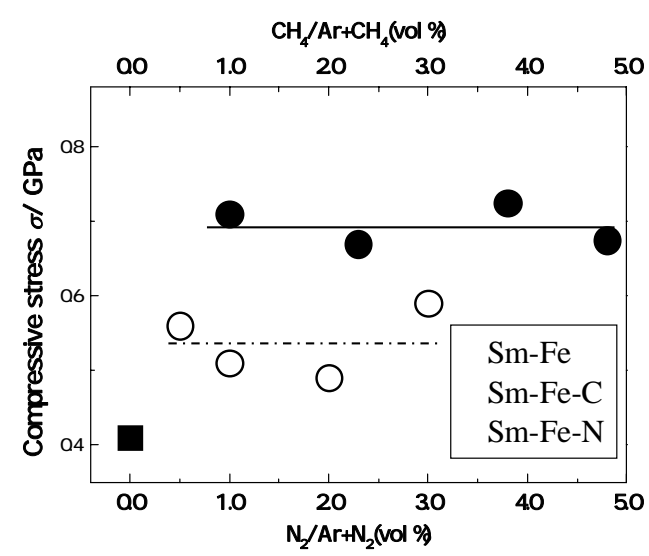

Fig. 4. Compressive stress of Sm-Fe-N and Sm-Fe-C Thin Film

本研究で作製した Sm-Fe 薄膜の内部応力はいずれも圧 縮方向の応力を示した。室素ガスを混合した Sm-Fe 薄膜 の内部応力は室素ガス混合量に関わらず、混合していな い Sm-Fe 薄膜より 0.3GPa 程度圧縮応力が増加した。ま た、メタンガスを混合した Sm-Fe 薄膜も窒素ガスを混合 した Sm-Fe 薄膜と同樣な傾向を示し、圧縮応力は 0.15GPa 程度増加した。これは、室素及び炭素原子が Sm-Fe 原子間に固溶した事により Sm-Fe 原子間距離が拡 張したためだと考えられる。しかし、圧縮応力の増加量 が微量で飽和していることから、圧縮応力の増加に寄与
する原子は微量であると考えられる。また、室素ガスに 比ベメタンガスを混合した薄膜の方が圧縮応力の増加率 が低かった。これは室素原子に比べ炭素原子の共有結合 半径が大きいことから、Sm-Fe 原子間に固溶できる原子 の数が少ないためであると考えられる。また、炭素原子 は室素原子と異なり固体として薄膜上に存在できるため、 Sm-Fe 原子間に固溶しなくても安定化することができる

このため、固溶量が少なく共有結合半径は室素ガスに 比べ大きいが内部応力は大きくならなかったものと考え られる。

III-C. Crystal structure of Sm-Fe-N and Sm-Fe-C Thin Film

スパッタリングガスに窒素ガスを混合し作製した各 Sm-Fe 薄膜の X 線回折の結果を Fig.5.に示す。

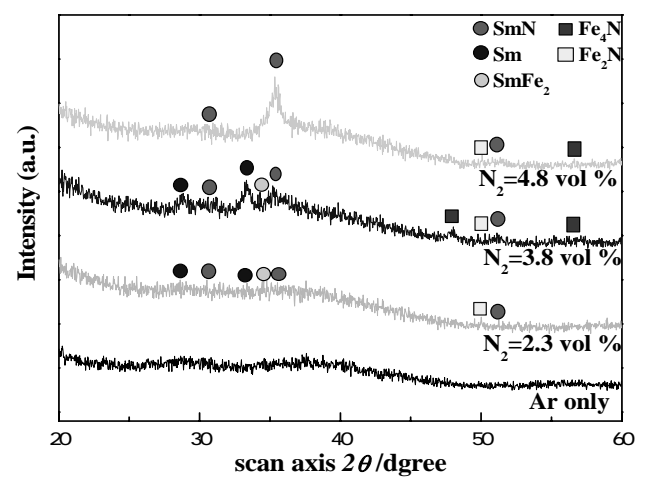

Fig. 5. X-ray Diffraction Pattern of Sm-Fe-N Thin Film

いずれの室素ガス混合量においても室化物と思われる ピークを除き明瞭なピークを示さなかった。このことか ら、本研究で作製した溥膜はアモルファス構造であると 考えられる。また、窒素ガス混合量が増加するに従い、 非磁性の SmN をはじめとする室化物やSmのピークが大 きくなる傾向が見られた。このことから $\mathrm{SmFe}_{2}$ が窒化物 の生成により不均質化していると考えられる。次に、

Fig.6.にメタンガスを混合し作製した各 Sm-Fe 薄膜のX 線回折の結果を示す。窒素ガスを混合した場合と同樣な 傾向が見られ、炭化物を除くと明瞭な結晶ピークは示さ ず、メタンガス混合量か増加するの従い非磁性 $\mathrm{SmC}_{2}$ や $\mathrm{SmFe}_{5}$ 等のピークが大きくなった。このことから $\mathrm{SmFe}_{2}$ が炭化物の生成により室素ガスを混合した場合と同樣に $\mathrm{SmFe}_{2}$ が不均質化していると考えられる。これらは、圧 縮応力の向上に寄与しなかった室素及び炭素原子が非磁 性である窒化物及び炭化物を生成し、光の影響によって 
Sm-Fe 薄膜の飽和磁歪量及び、最大磁歪感受率を低下し たと考えられる。

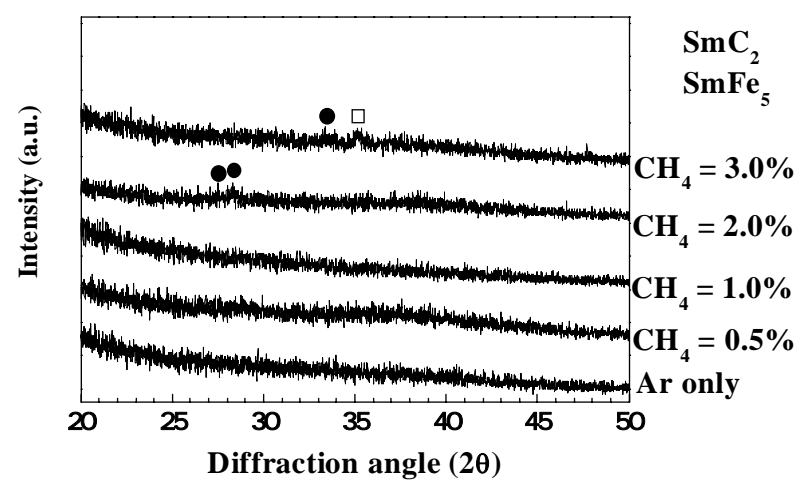

Fig. 6. X-ray Diffraction Pattern of Sm-Fe-C Thin Film

\section{CONCLUSION}

本研究では反応性 d.c.マグネトロンスパッタリング法 を用いて Sm-Fe-N 及び Sm-Fe-C 薄膜を作製した。室素ガ スやメタンガスの混合量か増加するに従って、飽和磁歪 量は減少した。今回作製した薄膜は室素ガス混合の場合 0.30GPa 程度、またメタンガス混合の場合 $0.15 \mathrm{GPa}$ の圧 縮応力の増加を示した。また、炭素ガスの混合に対し、 室素ガスを混合した薄膜のほうが大きな圧縮応力を示し た。この圧縮応力の影響により元素を微量固溶した場合、 磁歪感受率は向上するが固溶量の増加に伴い磁歪感受率 は低下した。

これより、Sm-Fe 薄膜に対する微量の異種元素の固溶 は、 Sm-Fe 薄膜の磁歪特性を向上させるが、過乘に固溶 させることで磁歪特性が低下することが明らかになった。

\section{REFERENCES}

${ }^{1}$ J.J.Rhyne and S. Legvold, Phys. Rev. A507,138 (1965)

${ }^{2}$ A.E.Clark, in E.P.Wohlfarth(ed.), "Ferromagnetic Materials”, Vol.1, North Holland, Amsterdam, 1980, Chap. 7.
${ }^{3}$ A.E.Clark and H.S.Belson, Phys. Rev. B5, 3642 (1972)

${ }^{4}$ A.E.Clark and H.S.Belson, IEEE Trans. Mag. MAG-8, 477(1972)

${ }^{5}$ M. Morimoto, T. Inagaki, T. Kobayashi, Y. Fujiwara, M. Masuda, S. Shiomi and T. Shiratori,Nippon Oyo Jiki Gakkaishi (in Japanese). 27, 269 (2003).

${ }^{6}$ S.M. Na, S.J. Suh and S.H. Lim: J. Appl. Phys.. 93 8507 (2003).

${ }^{7}$ T.M. Danh, N.H. Duc, H.N. Thanh and J. Teillet,J. Appl. Phys.. 87, 7208

${ }^{8}$ S. Esho and S. Fujiwara,AIP Conf. Proc., 34, 331 (1976).

${ }^{9}$ N. Heiman, A. Onton, D.F. Kyser, K. Lee and C.R. Guarniere,AIP Conf. Proc. 24, 573 (1975).

${ }^{10}$ R. Zwingman, W.L. Wilson, Jr. and H.C. Bourno,AIP Conf. Proc. 34, 334 (1976).

${ }^{11}$ J.A. Tornton and D.W. Hoffman,Thin Solid Films 171, 5(1989)

${ }^{12}$ H.Hauser,J.Appl.Phys.75,2584(1994)

${ }^{13}$ F.Schatz, M.Hirscher and M.Schnell, J.Appl.Phys. 76,5380(1994)

${ }^{14}$ S. Tsunashima, H. Takagi, K. Kamegaki, T. Fujii and S. Uchiyama,IEEE Trans. Magn. MAG-14, 844(1978)

${ }^{15}$ M. Takeuchi, Y. Matsumura and H. Uchida,J.Japan Inst. Metal 69,8667 (2005)

${ }^{16}$ A.C.Tam and H.Schroeder, J. Appl. Phys. 64 (1988) 5422-5424 